direct correspondence to:

MOL . 19990104.0476

Jim Boone

SAIC, 1180 Town Center Drive, Las Vegas, NV 89134

James.L.Boone.Jr @cpmx.saic.com

(702) $295-4925$ (voice)

(702) 295-5223 (FAX)

\title{
Sexing Young, Free-ranging Desert Tortoises (Gopherus agassizii) Using External Morphology
}

\author{
James L. Boonel and Eric A. Holt ${ }^{2,3}$ \\ ISAIC, Science Applications International Corporation, 1180 Town Center Drive, \\ Las Vegas, NV 89134 \\ 2EG\&G Energy Measurements, P.O. Box 1912, Las Vegas, NV 89125 \\ 3 Present address: Texas Cooperative Fish and Wildlife Research Unit, \\ Texas Tech University, Lubbock, TX 79409-2120.
}

\begin{abstract}
Adult desert tortoises (Gopherus agassizii) are sexually dimorphic in their external morphology, and characteristics of the plastron can be particularly useful for determining gender. However, sexual dimorphism in desert tortoises is associated with male secondary sexual characteristics, and therefore is not useful for assessing gender in young tortoises. We considered whether other: external characteristics were useful for determining gender of small tortoises by measuring 22 external characteristics on 105 tortoises (carapace length $52-299 \mathrm{~mm}$ ) and analyzing these data using discriminant function analysis. The discriminant models were capable of unambiguously assigning individuals as small as $140 \mathrm{~mm}$ to gender class, and by plotting the discriminant scores on carapace length, the model could be used to suggest the gender of even smaller tortoises (52-140 mm).
\end{abstract}


Keywords: desert tortoise, Gopherus agassizii, sexual dimorphism, gender, morphology, discriminant function analysis.

Methods for using external morphology to determine the gender of large desert tortoises (Gopherus agassizii) have been well known among herpetologists for years, as both Miller (1932) and Grant (1936) refer to the sexes without comment. Woodbury and Hardy (1948) provide quantitative measurements of male and female tortoises, and state that the genders generally can be identified using four characters. In males, the gular projection is longer, the plastron concavity is deeper, the tail is larger, and the overall size is greater than in females. However, these characters are not entirely satisfactory: "By studying these four characters, adults can usually be distinguished with certainty and a large percentage of young tortoises can be placed satisfactorily, but even with careful study, there are a few that cannot be properly allocated." (Woodbury and Hardy, 1948, p. 162).

Although using external morphology to determine gender of adult desert tortoises has generally been considered trivial, the logic of current methods is potentially circular: males are thought to have a specific set of characters, therefore a tortoise with those characters is a male. Independent estimates of gender (e.g., internal examination of gonads) are generally lacking.

Sexing juvenile desert tortoises is problematic because the characteristics used to determine gender are male secondary sexual characters that are generally not pronounced before males reach reproductive age (about $20 \mathrm{yr}$ for the animals used in this study), and therefore many biologists don't attempt to classify these tortoises to gender before their carapace length exceeds 180-200 $\mathrm{mm}$. Gender of desert tortoises can be determined with a high degree of certainty using testosterone levels in the blood (Rostal et al., 1994a), laparoscopy (visual examination of the gonads; Rostal et al., 1994a), ultrasonography (Rostal et al., 1994b), or x-ray visualization of eggs in utero, but these methods require techniques and laboratory facilities generally not available to field researchers. The difficulty of determining gender of small tortoises using external characteristics was evidenced by the unsuccessful attempt of Burke et al. (1994) to determine the 
gender of captive-reared desert tortoise hatchlings, and the efforts of Keller (1997) to determine gender in young Mauremys leprosa in Spain.

The ability to easily determine the gender of wild juvenile desert tortoises using extemal morphology would aid researchers studying demographics and other sex-dependent topics that aid in conservation efforts. The objectives of this study were to determine whether juvenile male and female tortoises in the northern Mojave Desert differ in external morphology, and if they do, to use discriminant analysis to find a small set of measurements that could be used in the field to determine gender before desert tortoises reach sexual maturity.

\section{Methods}

As part of a tortoise monitoring and research program conducted at Yucca Mountain, Nevada (Rautenstrauch et al., 1991), blood was drawn once per year (1993-1995) and a few measurements of the carapace and plastron were recorded (1989-1995). In 1992, 22 morphological measurement were taken on 105 tortoises. These measurements included: anal notch (AN), distance between the posterior edge of the plastron and the posterior edge of the carapace measured on the midline; minimum anal aperture (APER), estimated using circular cutouts of known diameter; anal width 1 (AW1), distance between the distal-most points of the anal shield (between the posterior-most points of the anal scutes); anal width 2 (AW2), distance between the lateral-most points of the suture between the anal and femoral scutes; carapace length (CL), maximum length of the carapace; foot widths (front-foot-right: FFR; front-foot-left: FFL; hind-foot-right: HFR; hindfoot-left: HFL), distance between the medial side of the inner toe-nail to the lateral side of the outer toe-nail; gular length (GULAR), distance from the middle of the seam between the gular and humeral scutes to the distal-most point of the longest gular; height (HGT), measured at the middle of vertebral scute 3; marginals 3-4 seam (M34), width of the carapace measured at the seam between marginal scutes 3 and 4; marginal 4 (M4), width of the carapace measured at the middle of marginal scute 4; marginals 7-8 seam (M78), width of the carapace measured at the seam between marginal scutes 7 and 8; plastron concavity (PC), depth of the femoral concavity measured by placing a straight-edge on the plastron at the midline and measuring the deepest point along the 
straight-edge; plastron notch length (PNN), maximum length of the plastron measured between the anterior and posterior notches; plastron tip length (PTT), maximum length of the plastron; anal shield thickness (SHLD), thickness of the anal shield measured at its posterior-most point; tail length (TL), measured from the cloaca to the tip; tail width (TW), measured at the base; mass (WT), total mass; and maximum width (WTH), maximum width of the carapace. Except as noted, measurements were made using calipers and recorded to the nearest $1 \mathrm{~mm}$ for characters generally exceeding $70 \mathrm{~mm}$, and $0.1 \mathrm{~mm}$ for shorter measurements.

In multivariate analyses, missing data were replaced with estimates generated by regressing the character of interest on the character with which it was most highly correlated. Most character were highly correlated $(r>0.95)$ with at least one other character. Overall, 62 of 2,310 data points (males: 38, 3.7\%; females: 13, 1.4\%; unknown gender: $11,2.6 \%$ ) were estimated. The majority of missing data were associated with male tails (TL: 10, TW: 14), female tails (TW: 4), and female gular lengths (4). In three cases, missing values were estimated based on measurements of the same animal in later years.

Gender was determined independently of external morphology for 35 females using testosterone levels in the blood, $x$-ray visualization of eggs, or observation of egg laying. Gender was determined for 13 males based on testosterone or observation of individuals engaged in copulatory behavior. Individuals mounted during copulatory encounters were not assumed to be female. Large individuals (CL > $200 \mathrm{~mm}$ ) of uncertain gender were assigned to a gender category based on overall morphology that was similar to the morphology of individuals of known gender. Each character was evaluated separately in univariate plots, regression, and preliminary multivariate analyses) and resulted in classifying 33 as male and 5 as female). For example, in a bivariate plot of carapace length versus plastron concavity, most individuals of known gender fall into discrete regions, and most large ( $\mathrm{CL}>200 \mathrm{~mm}$ ) individuals of unknown gender fall within the distribution of points defined by the individuals of known gender (Fig. 1). Nineteen smaller individuals of unknown gender were not assigned to gender a priori. This resulted in a priori classifications of 40 females, 46 males, and 19 of unknown gender. 
Data were grouped by various categories (e.g., males, females, gender unknown, large males, large female, etc.) and examined for conformation to assumptions of normality (inspection of plotted residuals) and homogeneity of variance $\left(\mathrm{F}_{\max }\right.$ test) among groups. Regardless of grouping, data were approximately normal, particularly for data sets containing only larger or only smaller individuals. Equality of variances among groups was rejected for PC and SHLD in a data set containing all males and females, but these characters responded favorably to a square-root transformation. In a data set of larger animals grouped by gender, PC required a square-root transformation, and in a data set of smaller animals grouped by gender, AW1 and AW2 required an $x^{2}$ transformation. In these and other data sets, several characters approached significance ( $\alpha=$ 0.05 ), but no single transformation equalized the variances among groups. Rather than apply different transformations to various characters in the data sets, univariate differences were tested using the nonparametric Mann-Whitney U-test (Sokal and Rohlf, 1981).

Three data sets were analyzed using discriminant analysis: all animals $(n=105)$, only larger animals ( $C L \geq 192 ; n=78$ ), and only smaller animals ( $C L \leq 217 ; n=39$ ). A carapace length of $192 \mathrm{~mm}$ was chosen as the minimum size for the data set containing larger animals because by this size, sexually dimorphic characteristics, such as depth of the plastron concavity (Fig. 1), were becoming apparent. A carapace length of $217 \mathrm{~mm}$ was chosen as the maximum size for the data set containing smaller animals because of sample size considerations and because it was not until this size that sexually dimorphic characteristics were fully developed (Fig. 1). For each data set, analyses were performed on untransformed data, and on various transformed data sets, using stepwise selection with prior probabilities set equal to group size (SPSS for the Macintosh; Norusis, 1990). Mass (WT) was not used in multivariate analyses. The test of equality of group covariance matrices (Box's $M$ test) was rejected for the untransformed data set containing all animals $(P<0.05)$, but the F-statistic $(2.98)$ was relatively small. Various transformations applied uniformly to the data did not improve the equality of variances. Equality of group covariances for large animals was also rejected $(P<0.05)$, but this F-statistics also was small $(2.56)$, as was the F-statistic for the data set of only small animals $(F=1.68, P=0.05)$. Departures from equality of 
group covariance matrices result in biases that, in the case of two-group discriminant analysis, fail to reject the null hypothesis of no difference between groups and tend to misclassify individuals by assigning too many observations to the group with the larger covariance matrix (Green, 1978). Because two-group discriminant analysis is believed to be robust to minor departures of equality of group covariances matrices (Green, 1978), the tests were conducted using untransformed data, but the results were interpreted with caution.

\section{Results}

In univariate analyses of larger $(\mathrm{CL} \geq 192 \mathrm{~mm}$ ) tortoises, the sexes differed (at the nominal rate of $P \leq 0.05$ ) for 19 of 22 characters (Table 1). If a Bonferroni adjustment to the alpha level was used $(\alpha=0.05 / 22=0.002 ;$ Rice, 1989), 11 tests would still be considered significant. Among the 11 significant tests were the three characters noted by Woodbury and Hardy (1948) as being useful for separating the sexes (gular length, plastron concavity, and tail length). For all characters, males tended to be larger than females, but there was overlap for every character. However, for larger animals ( $C L \geq 192 \mathrm{~mm}$ ), the plastron concavity of females never exceeded 3.9 $\mathrm{mm}$, and in no case was a male's plastron concavity shallower than $2.9 \mathrm{~mm}$ (Table 1). If only the largest animals are considered ( $C L>220 \mathrm{~mm}$ ), then all could be correctly assigned to gender class based on depth of the plastron concavity (female $\leq 3.9 \mathrm{~mm}$; male $\geq 4.8 \mathrm{~mm}$ ).

In univariate analyses of smaller ( $C L \leq 217 \mathrm{~mm}$ ) tortoises, the sexes differed (at the nominal rate of $P \leq 0.05$ ) for 4 of 22 characters (Table 2). If an adjustment were applied to the error rate $(P \leq 0.002)$, then no tests would be significant. However, even for these small animals, plastron concavity approached significance $(P=0.009)$ : female plastron concavity never exceeded $2.8 \mathrm{~mm}$, and that of the males always exceeded $0.8 \mathrm{~mm}$ (Table 2).

In the trivial case of using discriminant analyze to identify the gender of larger animals (CL $\geq 192$ ), all individuals of known gender classified correctly. Although it is generally considered easy to classify adults based on external morphology, the model required nine characters to correctly classify all individuals (Table 3, "Only Adults"). The eigenvalue of this function was 5.674 , and the canonical correlation was 0.922 . 
Using the data set composed of all animals of known gender, discriminant analysis selected 11 measurements and correctly classified all but one tortoise (Male \#493, Fig. 1). When the 19 small animals of unknown gender were classified using this discriminant function (Table 3, "All Animals"), two were classified as males and 17 were classified as females. Despite the apparent success of this model, it is likely that some small males were incorrectly classified as females because the sex ratio of adult tortoises at Yucca Mountain was approximately 1:1.

Although the sample size was small $(n=39)$, when small animals ( $C L \leq 217)$ were subjected to discriminant analysis, all 20 individuals of known gender classified correctly. When the 19 small individuals of unknown gender were classified with this discriminant function (Table 3, "Only Small Animals"), all tortoises fell cleanly into the two groups using only five characters (Fig. 2). The eigenvalue of this function was 3.056 , and its canonical correlation was 0.868 . The program estimated the probability of group membership, and most (13 of 19) were assigned to gender class with greater than $99 \%$ certainty; only one fell as low as $78 \%$.

\section{Discussion}

This study applies statistical rigor to long-standing assumptions about our ability to identify large male and female tortoises in the eastern Mojave Desert using external morphology, and it supports the conclusion that characters traditionally used (plastron concavity, gular length, and tail

length) are useful. In univariate analyses, these characters has the largest Z-scores (Table 1 ). Two other characters, the distance between the posterior-most points of the anal scutes (AW1;Z = $-3.94)$ and front-foot widths $(\mathrm{Z} \leq-4.14)$ may also be useful characters. For larger animals ( $C L>$ $220 \mathrm{~mm}$ ), the depth of the plastron concavity alone is sufficient to determine gender, and use of the other traditional characters can add support to one's decisions on gender determination.

However, in the northem Mojave Desert, it is not until these animals reach a carapace length of about $220 \mathrm{~mm}$ that one can be certain of correctly identifying the gender of all tortoises using a few external characters. For example, when tortoise $\$ 493$ (male, determined by testosterone level) was first measured in 1992, he had a carapace length of $179 \mathrm{~mm}$, an unusually flat plastron ( $\mathrm{PC}=0.8 \mathrm{~mm}$ ), and he looked like a female (Fig. 1). However, as he aged from 1992 
to 1995 , his plastron concavity rapidly deepened, and it is likely that by 1996 , the depth of his plastron concavity would have exceeded that of most or all females.

Despite the apparent success of the model for smaller animals ( $C L \leq 217$ ), when discriminant scores were plotted against carapace length (a proxy for age; Fig. 2), it appeared that "subadult animals" ( $140<\mathrm{CL}<200$ ) were properly classified, but smaller animals were only classified as females, a result similar to Keller (1997). While it was possible that all of the smaller animals were female, it was more likely that some of these smallest animals ( $C L<140$ ) were males that had not yet begun to acquire secondary sexual characters and therefore were classified erroneously as females. Despite the probable misclassification, when discriminant scores were plotted against carapace length (Fig. 2), the relationship invites speculation that it is possible to predict gender on animals as small as $90-110 \mathrm{~mm}$. One individual $(\mathrm{CL}=108 \mathrm{~mm})$ had a discriminant score of 0.19 (Fig. 2), a score that appears relatively large for so small a female; it is likely that as it ages, its score will continue to increase, and it would later be classified as a male. Another individual $(\mathrm{CL}=111 \mathrm{~mm}$ ) has a discriminant score of -1.14 (Fig. 2), a score that appears reasonable for a small female.

Only three characters were important for separating males and females in all three data sets (Table 3). In each case, deep plastron concavities (always the largest coefficient) and wide frontright feet (always a large coefficient) were associated with males. Gular length was important in each case, but a long gular was associated with males only for the data sets containing all animals and large animals. Contrary to what may be expected, for the smaller tortoises used in this study, a long gular was associated with females. Four characters were selected in two cases. Wide tail and anal widths (AW1, AW2), and thick anal shields (always a large coefficient) were associated with females. Hind foot-width entered the model for small and large animals, but with different signs. For large animals, a wide foot was associated with males, but for small animals it was associated with females.

This study was based on desert tortoises from the northern edge of their range, and because the shape of the carapace is known to be influenced by environmental factors (Reiber and 
McDaniel, 1995), these results may not apply elsewhere. However, these models selected characters that are believed useful for determining gender throughout the species' range, and others have shown that tortoise populations in the eastem Mojave do not differ markedly from one another (Germano, 1993; Weinstein and Berry, in lit); therefore, these models likely are useful over a wider area than just Yucca Mountain (i.e., at least the eastern Mojave Desert).

These results provide a tool for estimating the gender of small tortoises $(C L \leq 217)$ from the eastern Mojave Desert that have not developed secondary sexual characteristics to a sufficient degree to allow easy gender determination in the field. To use this tool for small tortoises, researches can measure the five important characters ("Only small Animals"; Table 3), multiply each measurement by its corresponding discriminant function coefficient, sum the products, and add the constant. If the resulting score exceeds 0.5 , the specimen is most likely a male; otherwise it is most likely a female. For the smallest animals ( $\mathrm{CL}<140$ ), the score and carapace length can be plotted on Figure 2 for comparison with the results of this model, possibly permitting a judgment to be made regarding gender identification. While the sample used to build the model was small, it correctly classified all small tortoises ( $140 \leq \mathrm{CL} \leq 217)$ of known gender, and in posterior classification of individuals of unknown gender within this size range. it unambiguously assigned individuals to gender.

\section{Acknowledgments}

Elizabeth A. LaRue, Patrick E. Lederle, and Kurt R. Rautenstrauch reviewed and provided suggestions that improved this manuscript. Tortoises were handled under Federal (PRT-683011 and PRT-781234) and State (S0446, S1595, S3108, S5041, S6941, and 9060) permits. This research was supported and managed by the U. S. Department of Energy, Yucca Mountain Site Characterization Office as part of the Civilian Radioactive Waste Management Program under contracts DE-AC08-93-NV-11265 and DE-ACO1-91-RW-00134. 


\section{Literature Cited}

Burke, R.L., Jacobson, E.R., Griffith, M.J., and Guillette, L.J. 1994. Non-invasive sex identification of juvenile gopher and desert tortoises (genus Gopherus). Amphibia-Reptilia 15:183-189.

Germano, D.J. 1993. Shell morphology of North American tortoises. Am. Midl. Nat. 129:319-335.

Grant, C. 1936. The Southwestem Dessert Tortoise, Gopherus agassizii. Zoologica, 21:225-229.

Green, P.E. 1978. Analyzing multivariate data. Illinois: Dryden Press, 519 pp.

Keller, C. 1997. Discriminant analysis for sex determination in juvenile Mauremys leprosa. J. Herp. 31:456-459.

Miller, L. 1932. Notes on the desert tortoise (Testudo agassizii). Trans. San Diego Soc. Nat. Hist. 18:187-208.

Norusis, M.J. 1990. SPSS Base System Users Guide. Chicago: SPSS, Inc., 520 pp.

Rautenstrauch, K.R., Cox, M.K., Doerr, T.B., Green, R.A., Mueller, J.M., O'Farrell, T.P., and Rakestraw, D.L. 1991. Management and research of desert tortoises for the Yucca Mountain Project. Proc. High Level Radioactive Waste Mgmt Conf. 2:1449-1455.

Reiber, C.L., and McDaniel, M. 1995. Temperature dependent morphological changes and their resulting influence on behavioral thermoregulation in the desert tortoise (Gopherus agassizii). Am. Zool. 35:37a.

Rice, W.R. 1989. Analyzing tables of statistical tests. Evol. 43:223-225.

Rostal, D.C., Grumbles, J.S., Lance, V.A., and Spotila, J.R. 1994a. Non-lethal sexing techniques for hatchling and immature desert tortoises (Gopherus agassizii). Herp. Monogr. 8:83-87.

Rostal, D.C., Lance, V.A., Grumbles, J.S., and Alberts, A.C. 1994b. Seasonal reproductive cycle of the desert tortoise (Gopherus agassizii) in the eastern Mojave Desert. Herp. Monogr. 8:72-82.

Sokal, R.R., and Rohlf, F.J. 1981. Biometry. Second Ed. San Francisco: Freeman, 859 pp. 
Turner, F.B., Hayden, P., Burge, B.L., and Roberson, J.B. 1986. Egg production by the desert tortoise (Gopherus agassizii) in California. Herpetologica 42:93-104.

Woodbury, A.M., and Hardy, R. 1948. Studies of the desert tortoise, Gopherus agassizii. Ecol. Monogr. 18:145-200. 


\section{Figure Legends}

Figure 1. Depth of the plastron concavity in relation to size (carapace length) with a priori gender groupings. Individuals were assigned to gender category based on non-morphological criteria (gender certain) or based on morphology that was similar to morphology of known animals (gender uncertain). Smaller animals were not assigned to gender based on morphology (juvenile uncertain). The position (stars) and trajectory (dotted line) of Male \#493 is shown for each year from 1992 to 1995.

Figure 2. Distribution of discriminant function scores from the model using only small animals (CL $\leq 217 \mathrm{~mm}$ ) in relation to tortoise size (carapace length). Young males and females (140 $\leq C L \leq 217)$ of known gender classified correctly, but all smaller $(C L<140)$ animals of unknown gender were assigned to the female class. 
Table 1. Sample size (N), mean ( $\bar{x}$ ), standard crror (SE), minimum (Min) and maximum (Max) of measurements of frec-ranging large (CL $\geq 192 \mathrm{~mm}$ ) desert tortoises (Gopherus agassizii) at Yucca Mountain, Nevada. Significance of size differences between females and males was tested using Mann-Whitney U-tests.

\begin{tabular}{|c|c|c|c|c|c|c|c|c|c|c|c|c|}
\hline \multirow[b]{2}{*}{ Character } & \multicolumn{5}{|c|}{ Malc } & \multicolumn{5}{|c|}{ Fcinalc } & \multicolumn{2}{|c|}{ U-test } \\
\hline & $\mathbf{N}$ & $\bar{x}$ & SE & Min & Max & $\mathbf{N}$ & $\bar{x}$ & SE & Min & Max & $Z$ & $\boldsymbol{P}$ \\
\hline Anal Aperture (APER) & 39 & 28.4 & 0.91 & 17.2 & 38.1 & 38 & 27.4 & 0.72 & 18.7 & 38.1 & -0.88 & $\overline{0.381}$ \\
\hline Anal Nolch (AN) & 39 & 32.8 & 1.01 & 20.0 & 43.0 & 38 & 32.2 & 0.80 & 21.5 & 41.9 & -0.46 & 0.647 \\
\hline Anal Shicld Thickness (SHLD) & 38 & 2.9 & 0.22 & 0.8 & 6.1 & 38 & 2.0 & 0.14 & 0.9 & 4.0 & -3.03 & 0.002 \\
\hline Anal Width I (AWI) & 39 & 51.9 & 1.56 & 31.5 & 70.7 & 38 & 43.7 & 0.84 & 29.9 & 52.8 & -3.94 & $<0.001$ \\
\hline Anal Width 2 (AW2) & 39 & 68.6 & 1.31 & 52.6 & 84.5 & 38 & 62.6 & 1.00 & 49.0 & 78.0 & -3.35 & 0.001 \\
\hline Carapace Length (CL) & 39 & 252.9 & 4.25 & 199 & 299 & 38 & 240.0 & 3.24 & 192 & 275 & -2.30 & 0.021 \\
\hline Front Foot Width, Left (FFL) & 38 & 37.1 & 0.72 & 28.5 & 45.9 & 37 & 32.9 & 0.50 & 27.1 & 39.9 & -4.14 & $<0.001$ \\
\hline Front Foot Width, Right (FFR) & 37 & 37.5 & 0.71 & 28.6 & 46.4 & 37 & 32.6 & 0.49 & 26.3 & 39.0 & -4.75 & $<0.001$ \\
\hline Gular Lenglh (GULAR) & 35 & 47.1 & 1.17 & 33.0 & 59.6 & 35 & 38.6 & 0.87 & 27.2 & 47.8 & -4.80 & $<0.001$ \\
\hline Hind Foot Width, Left (HFL) & 39 & 34.2 & 0.73 & 23.5 & 42.5 & 37 & 30.8 & 0.57 & 22.8 & 36.8 & -3.29 & 0.001 \\
\hline Hind Foot Width, Right (HFR) & 39 & 34.3 & 0.74 & 25.6 & 43.2 & 37 & 31.0 & 0.58 & 23.9 & 38.1 & -3.26 & 0.001 \\
\hline Plastron Concavity (PC) & 39 & 10.1 & 0.60 & 2.9 & 17.2 & 37 & 1.8 & 0.16 & 0.0 & 3.9 & -7.43 & $<0.001$ \\
\hline Tail Length (TL) & 39 & 30.1 & 1.01 & 17.1 & 40.7 & 31 & 22.2 & 0.80 & 9.2 & 32.5 & -4.93 & $<0.001$ \\
\hline Tail Width (TW) & 35 & 20.7 & 0.84 & 10.4 & 32.2 & 28 & 20.0 & 0.62 & 13.5 & 27.2 & -0.68 & 0.498 \\
\hline Height (HGT) & 39 & 105.3 & 1.50 & 85 & 125 & 36 & 100.4 & 1.13 & 84 & 115 & -2.33 & 0.020 \\
\hline M 3-4 Seam (M34) & 39 & 173.5 & 3.16 & 131 & 209 & 37 & 161.1 & 2.16 & 131 & 186 & -3.16 & 0.00 \\
\hline M4 (mid) (M4) & 39 & 185.3 & 3.19 & 144 & 220 & 37 & 173.9 & 2.29 & 142 & 202 & -2.87 & 0.00 \\
\hline Marginals 7-8 Seam (M78) & 39 & 196.8 & 3.52 & 151 & 236 & 38 & 185.2 & 2.63 & 151 & 216 & -2.69 & 0.00 \\
\hline Mass (WT) & 38 & 2826.3 & 138.2 & 1376 & 4681 & 37 & 2330.8 & 80.7 & $1246 ?$ & 3371 & -2.64 & 0.00 \\
\hline Maximum Width (WTH) & 39 & 200.1 & 3.60 & 154 & 239 & 38 & 188.6 & 2.67 & 152 & 220 & -2.64 & 0.00 \\
\hline Plastron Length (PNN) & 39 & 235.4 & 4.42 & 176 & 295 & 37 & 222.1 & 3.29 & 175 & 265 & -2.37 & 0.01 \\
\hline Plastron Length (PTT) & 39 & 255.6 & 4.33 & 200 & 310 & 38 & 243.6 & 3.38 & 195 & 288 & -2.23 & 0.026 \\
\hline
\end{tabular}


Table 2. Sample size (N), mean ( $\bar{x})$, standard error (SE), minimum (Min) and maximum (Max) of measurements of free-ranging small (CL $\leq 217 \mathrm{~mm}$ ) Desent Tortoises (Gopherus agassizii) of known gender at Yucca Mounlain, Nevada. Significance of size differences between females and males was tesied using Mann-Whitncy U-Icsts.

\begin{tabular}{|c|c|c|c|c|c|c|c|c|c|c|c|c|}
\hline \multirow[b]{2}{*}{ Character } & \multicolumn{5}{|c|}{ Malc } & \multicolumn{5}{|c|}{ Fcmalc } & \multicolumn{2}{|c|}{ U-test } \\
\hline & $\mathbf{N}$ & $\bar{x}$ & SE & Min & Max & $\mathbf{N}$ & $\bar{x}$ & SE & Min & Max & $Z$ & $P$ \\
\hline Anal Aperture (APER) & 6 & 19.7 & 1.10 & $\overline{17.2}$ & 23.8 & 14 & 17.8 & 1.55 & 10.3 & 28.6 & -1.03 & 0.30 \\
\hline Anal Notch (AN) & 6 & 23.0 & 1.33 & 20.0 & 27.9 & 14 & 20.3 & 1.70 & 11.7 & 33.6 & -1.07 & 0.2 \\
\hline Anal Shield Thickness (SHLD) & 6 & 1.3 & 0.16 & 0.8 & 1.9 & 14 & 1.4 & 0.08 & 0.9 & 1.9 & -0.17 & 0.8 \\
\hline Anal Width I (AWI) & 6 & 36.5 & 1.33 & 31.5 & 40.4 & 14 & 30.9 & 2.11 & 18.1 & 44.2 & -1.90 & 0.0 \\
\hline Anal Width 2 (AW2) & 6 & 53.4 & 1.77 & 45.9 & 58.3 & 14 & 43.7 & 3.01 & 24.0 & 60.5 & -1.77 & 0.07 \\
\hline Carapace Length (CL) & 6 & 201.7 & 5.14 & 179 & 217 & 14 & 177.0 & 7.98 & 129 & 212 & -1.49 & 0.13 \\
\hline Front Foot Width, Left (FFL) & 6 & 29.0 & 0.97 & 25.4 & 32.8 & 14 & 24.4 & 1.11 & 17.4 & 31.0 & -2.56 & 0.0 \\
\hline Front Foot Width, Right (FFR) & 5 & 29.3 & 0.93 & 25.7 & 32.8 & 14 & 24.4 & 1.16 & 17.8 & 31.4 & -2.04 & 0.0 \\
\hline Gular Length (GULAR) & 5 & 33.9 & 2.62 & 23.3 & 43.4 & 14 & 29.2 & 1.44 & 21.7 & 37.7 & -1.30 & 0.19 \\
\hline Hind Foot Width, Left (HFL) & 6 & 25.9 & 1.18 & 21.4 & 29.0 & 14 & 22.4 & 1.24 & 14.2 & 30.8 & -1.57 & 0.11 \\
\hline Hind Foot Width, Right (IIFR) & 6 & 25.9 & 0.88 & 22.0 & 28.5 & 14 & 22.4 & 1.25 & 14.5 & 29.3 & -1.61 & 0.108 \\
\hline Plastron Concavity (PC) & 6 & 3.5 & 0.71 & 0.8 & 5.9 & 13 & 1.2 & 0.23 & 0.0 & 2.8 & -2.63 & 0.009 \\
\hline Tail Length (TL) & 6 & 18.5 & 1.98 & 10.0 & 24.5 & 11 & 16.7 & 1.71 & 9.2 & 27.5 & -0.10 & 0.92 \\
\hline Tail Width (TW) & 5 & 14.6 & 1.62 & 10.4 & 20.3 & 9 & 14.8 & 1.13 & 9.7 & 22.5 & -0.47 & 0.6 \\
\hline Height (HGT) & 6 & 89.5 & 3.53 & 75 & 100 & 14 & 79.8 & 2.79 & 60 & 93 & -2.02 & 0.04 \\
\hline M 3-4 Seam (M34) & 6 & 134.5 & 5.23 & 111 & 148 & 14 & 120.4 & 6.01 & 85 & 158 & -1.44 & 0.14 \\
\hline M4 (mid) (M4) & 6 & 146.3 & 4.55 & 127 & 161 & 14 & 130.2 & 5.97 & 95 & 165 & -1.44 & 0.14 \\
\hline Marginals 7-8 Seam (M78) & 6 & 154.5 & 5.08 & 133 & 171 & 14 & 136.0 & 6.43 & 100 & 169 & -1.49 & 0.13 \\
\hline Mass (WT) & 5 & 1400.7 & 140.79 & 760 & 1783 & 14 & 1057.5 & 143.13 & 391 & 1882 & -1.30 & 0.15 \\
\hline Maximum Width (WTH) & 6 & 157.0 & 4.94 & 136 & 173 & 14 & 138.6 & 6.56 & 102 & 174 & -1.44 & 0.149 \\
\hline Plastron Length (PNN) & 6 & 186.0 & 7.19 & 164 & 212 & 14 & 165.9 & 7.80 & 118 & 206 & -1.44 & 0.14 \\
\hline Plastron Length (PTT) & 6 & 206.2 & 6.26 & 185 & 229 & 14 & 182.0 & .59 & 128 & 227 & -1.49 & 0.138 \\
\hline
\end{tabular}


Table 3. Unstandardized discriminant function coefficients that separate free-ranging male and female desert tortoises (Gopherus agassizii) at Yucca Mountain, Nevada. Three sets of discriminant coefficients are presented: one set for separating all animals ( $52 \leq \mathrm{CL} \leq 299$ $\mathrm{mm}$ ), one set for separating only larger animals ( $C L \geq 192 \mathrm{~mm}$ ), and another set for separating only smaller individuals ( $C L \leq 217 \mathrm{~mm}$ ). The functions correctly classify 98 , 100 , and $100 \%$ of individuals of known gender, respectively.

\begin{tabular}{llll}
\hline \multicolumn{1}{c}{ Character } & All Animals & Only Adults & Only Small Animals \\
\hline Minimum anal aperture (APER) & -0.104 & & \\
Anal width 1 (AW1) & -0.063 & -0.055 & \\
Anal width 2 (AW2) & 0.108 & & \\
Front foot right (FFR) & 0.315 & 0.242 & 0.608 \\
Gular length (GULAR) & 0.039 & 0.082 & -0.254 \\
Hind foot right (HFR) & & 0.101 & -0.128 \\
Carapace length (CL) & -0.046 & -0.054 & \\
Anal notch (AN) & & -0.105 & \\
Plastron concavity (PC) & 0.420 & 0.498 & \\
Anal shield thickness (SHLD) & -0.364 & -0.395 & \\
Plastron length (PIT) & 0.026 & & -0.194 \\
Tail width (TW) & -0.056 & -0.062 & \\
Tail length (TL) & -1.003 & & \\
Maximum width (WTH) & & & \\
(Constant) & & & \\
\hline
\end{tabular}




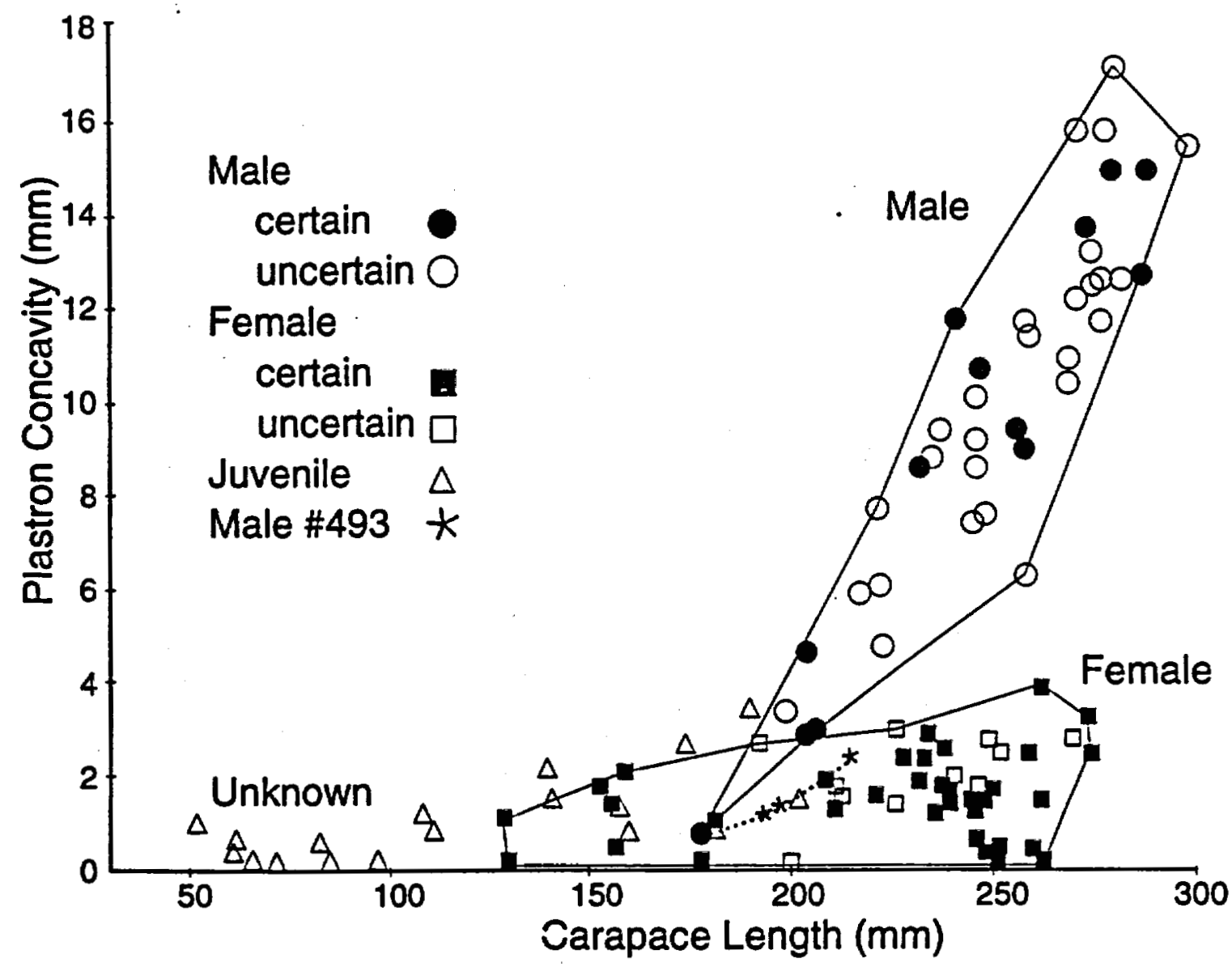

Figure 1. Depth of the plastron concavity in relation to size (carapace length) with a priori gender groupings. Individuals were assigned to gender category based on nonmorphological criteria (gender certain) or based on morphology that was similar to morphology of known animals (gender uncertain). Smaller animals were not assigned to gender based on morphology (juvenile uncertain). The position (stars) and trajectory (dotted line) of Male \#493 is shown for each year from 1992 to 1995.

Note: final figure can be printed at any scale on slick paper (and without the caption). 


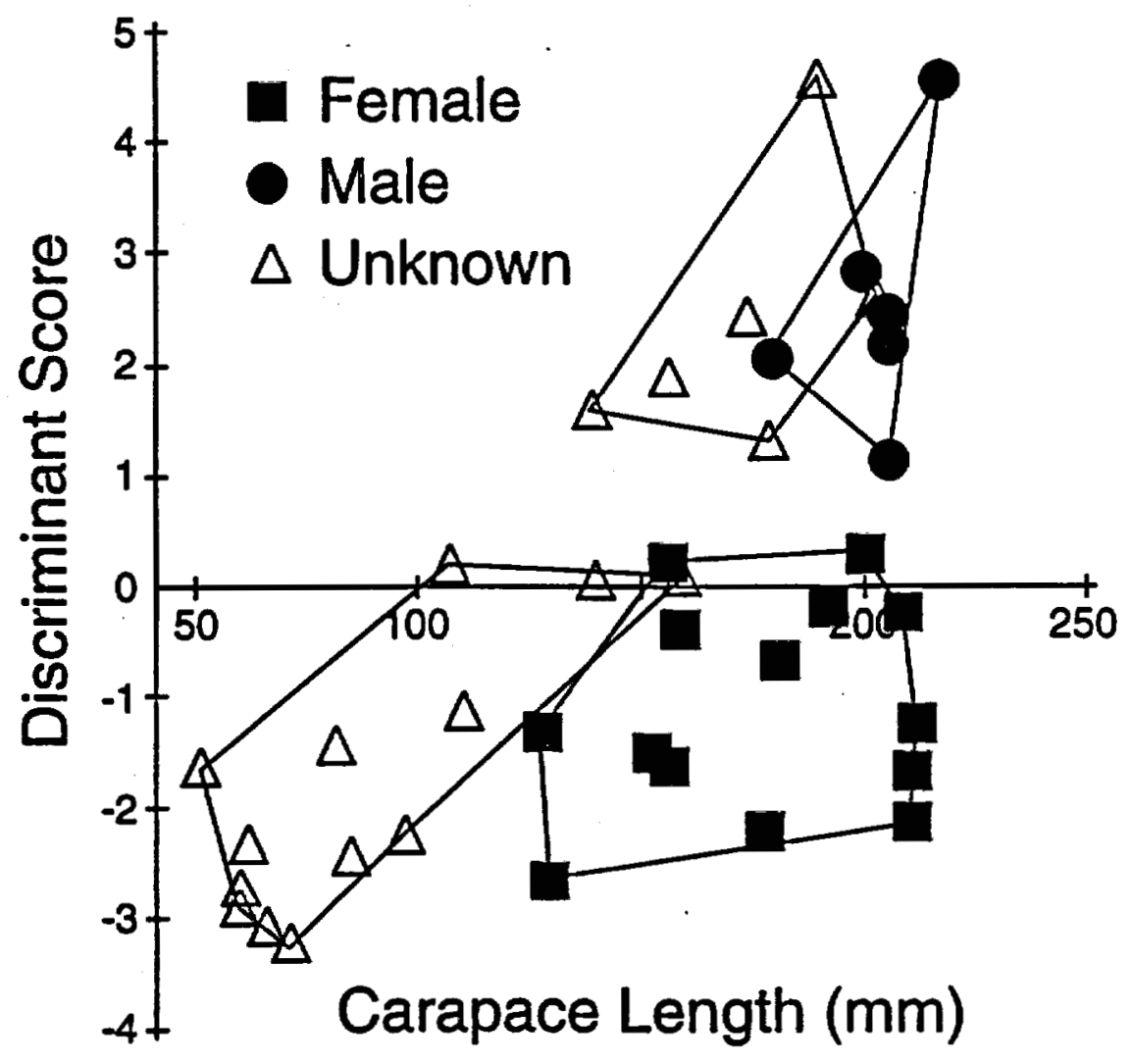

Figure 2. Distribution of discriminant function scores from the model using only small animals (CL $\leq$ $217 \mathrm{~mm}$ ) in relation to tortoise size (carapace length). Young males and females $(140<\mathrm{CL}<210)$ of known gender classified correctly, but all smaller ( $C L<140)$ animals of unknown gender were assigned to the female class.

Note: final figure can be printed at any scale on slick paper (and without the caption). 


\section{Disclaimer}

Tortoises were handled under permits PRT-683011 and PRT-781234 from the U.S. Fish and Wildife Service, and S-0446, S-1595, S-3108, S-5041, S-6941, and S-9060 from the Nevada Division of Wildlife. This research was supported and managed by the U.S. Department of Energy, Yucca Mountain Site Characterization Office, as part of the Civilian Radioactive Waste Management Program under contracts DE-AC08-88NV10617, DE-AC08-93NV11265, and DEACO1-91-RW-00134. The U.S. Government retains a nonexclusive, royalty-free license to publish or reproduce the published form of this contribution, or to allow others to do so, for U.S. Government purposes. This paper was prepared as an account of work sponsored by an agency of the United States Government. Neither the United States nor any agency thereof, nor any of their employees, makes any warranty, express or implied, or assumes any legal liability or responsibility for the accuracy, completeness, or usefulness of any information, apparatus, product, or process disclosed, or represents that its use would not infringe privately owned rights. Reference herein to any specific commercial product, process, or service by trade name, trademark, manufacturer, or otherwise, does not necessarily constitute or imply its endorsement, recommendation, or favoring by the United States Government or any agency thereof. The views and opinions of authors expressed herein do not necessarily state or reflect those of the United States Government or any agency thereof. 